\title{
Religious coping and God locus of health control: their relationships to health quality of life among people living with HIV in Malaysia
}

\section{BACKGROUND}

The aim of the report was to explore the relationships between God health locus of control, religious coping, and health quality of life among people living with HIV (PLWH).

\section{PARTICIPANTS AND PROCEDURE}

Purposive sampling was used to recruit $117 \mathrm{PLWH}$ who have a religion, and the survey method was used to collect data.

\section{RESULTS}

The results showed that God health locus of control was significantly positively correlated with negative religious coping, and negative religious coping was significantly negatively correlated with health quality of life. In addition, negative religious coping is the mediator of the indirect effect of God health locus of control on the quality of life.

\section{CONCLUSIONS}

More training to reduce the use of negative religious coping among PLWH who have a religion in Malaysia will be helpful to improve their overall function quality of life (QoL).

\section{KEY WORDS}

religious coping; health locus of control; health-related quality of life; people living with HIV

Organization - Universiti Tunku Abdul Rahman, Kampar, Perak, Malaysia

AUthors' CONTRiButions - A: Study design - B: Data collection · C: Statistical analysis · D: Data interpretation ·

E: Manuscript preparation · F: Literature search · G: Funds collection

CORresponding Author - Poh Chua Siah, Ph.D., Universiti Tunku Abdul Rahman, Jalan Universiti, Bandar Barat

Kampar, 31900 Perak, Malaysia, e-mail: siahpc@gmail.com

TO CITE THIS ARTICLE - Siah, P. C., \& Tan, J. H. (2017). Religious coping and God locus of health control: their

relationships to health quality of life among people living with HIV in Malaysia. Health Psychology Report, 5(1), 41-47.

doi: 10.5114/hpr.2017.62724

RECEIVED 01.04.2016 · REVIEWED 01.06.2016 · ACCEPTED 02.07.2016 · PUBLISHED 17.10.2016 


\section{BACKGROUND}

The estimated global number of people living with HIV (PLWH) in the year 2013 was approximately 35 million. Due to the highly active antiretroviral treatment (HAART), both AIDS-related deaths and the new infection rate have been declining (Joint United Nations Programme on HIV/AIDS, 2014). Therefore, researchers and clinicians have paid attention to improving the quality of life (QoL) among PLWH.

Poh Chua Siah, Jiunn Han Tan

Quality of life is defined as an "individual's perceptions in the context of their culture and value systems, and their personal goals, standards and concerns. It is a broad ranging concept affected in a complex way by the person's physical health, psychological state, level of independence, social relationships, personal beliefs and their relationship to salient features of their environment" (World Health Organization, 1997).

Quality of life is an important measure for guiding healthcare (Collins, Hogan, \& Desai, 1991), as it is a multidimensional concept that cannot be simply equated with health status, lifestyle, life satisfaction, mental state or well-being (The WHOQOL Group, 1998). Therefore, the application of QoL has been extended to the health area, labelled health-related QoL (HQoL), and defined as the extent to which one's usual or expected physical, emotional, and social health are affected by a medical condition or its treatment (Cella \& Bonomi, 1995).

Among all of the different types of QoL measurements, HIV/AIDS-targeted quality of life (HAT-QoL) is a QoL measurement that has been developed and specially targeted at PLWH (Holmes \& Shea, 1997). Poor HAT-QoL has been reported to be associated with depression, personality disorder and physical symptoms (Gore-Felton et al., 2006; Hansen, Vaughan, Cavanaugh, Connell, \& Sikkema, 2009; Lorenz, Cunningham, Spritzer, \& Hays, 2006).

The HQoL of PLWH was also found to be relevant to the individual differences in health locus of control (HLoC) (Préau et al., 2005). Health locus of control is defined as the perception of control that an individual has over the health events in their lives (Levenson, 1972). Health locus of control originates from the locus of control that was first proposed by Rotter (1954). The concept was then included in the framework of the social learning theory by Bandura (1977), and research on the locus of control was then further extended to the areas of health (Levenson, 1972).

The multidimensional HLoC scale (MHLoC) is a measurement that was designed to measure HLoC (Wallston, Stein, \& Smith, 1994). The MHLoC scale categorizes HLoC as either internal or external (chance, doctors and powerful others). Those individuals with an internal HLoC have a stronger belief that they are in control of their health outcomes.
Consequently, they are more likely to engage in preventative behaviour. Those individuals with an external HLoC believe that their health outcomes are primarily controlled by outside forces, or are inevitable. Consequently, they are less likely to engage in preventative behaviour (Wallston, Wallston, \& DeVellis, 1978). The God HLoC scale was added to the original MHLoC Form C. This scale was designed to assess religious health beliefs (Wallston et al., 1999).

Studies found inconsistent results of God HLoC with QoL; God HLoC was found to be associated with lower alcohol use in undergraduate students (Kuwahara et al., 2004) but with low acceptance of clinical breast examinations and mammography recommendations among African American women and low physical activity levels among African American adults (Franklin, Schlundt, \& Wallston, 2008; Kinney, Emery, Dudley, \& Croyle, 2002).

Besides HLoC, religious coping was also found to be relevant to the HQoL of PLWH (Trevino et al., 2007). Religious coping is defined as "ways of understanding and dealing with negative life events that are related to the sacred" (Pargament \& Raiya, 2007, p. 743). In other words, religious coping is about how an individual may turn to a higher power and the use of religious beliefs or practices to cope with stressful life events (Pargament, 1997).

Overall, such religious coping behaviour can be categorized as positive religious coping and negative religious coping. Positive religious coping reflects a generally secured relationship with a higher power, such as seeking a divine or spiritual connection and support and benevolent religious reappraisals. Negative religious coping or religious struggle generally reflects the tension, conflict, and struggle with a higher power, and these intrapersonal struggles involve negative emotions towards the higher power, such as anger, questioning the power of God, and feelings of abandonment (Pargament, Feuille, \& Burdzy, 2011).

Positive religious coping is found to be associated with positive psychological adjustment when facing stressful situations, which improves physical health, positive affect and life satisfaction. Negative religious coping is found to be associated with negative psychological adjustment when facing stressful situations, which increases levels of psychopathology, poorer physical health, a high level of depressive symptoms and a low level of QoL (Ano \& Vasconcelles, 2005; Lee, Nezu, \& Nezu, 2014; McConnell, Pargament, Ellison, \& Flannelly, 2006; Pargament, Koenig, Tarakeshwar, \& Hahn, 2004).

\section{AIM OF THE STUDY}

A literature review has shown the associations between God HLoC and HQoL, and the associations between religious coping and HQoL among PLWH. 
Nonetheless, in our knowledge, no similar study has been conducted to examine the relationships among these three variables together in PLWH. Since simply holding certain religious beliefs may not be sufficient in assisting an individual to cope with major life stressors, an individual must activate his or her religion and integrate their beliefs into coping responses so that he/she can cope with the life stressors effectively (Pargament, 1997). Accordingly, this report expects that religious coping could be the mediator of the effects of God HLoC on HQoL. Nonetheless, we only include overall function QoL in the data analyses of this report, since overall function QoL is a combination of physical, role and social QoL (Holmes \& Shea, 1999).

The aims of this report are therefore to explore the following:

1. What are the relationships between God HLoC, religious coping and overall function HQoL?

2. Does religious coping mediate the relations between God HLoC and overall function HQoL?

\section{PARTICIPANTS AND PROCEDURE}

\section{PARTICIPANTS}

One hundred and seventeen PLWH from five religious-based non-government organizations (NGOs) were invited to participate in this study through the purposive sampling method. About $75 \%$ of them were male. The age range was 17 to $70(M=40.25$, $S D=11.57)$. Most of them were adhering to medication $(78.60 \%)$, male $(74.80 \%)$, already married or in a relationship $(69.00 \%)$, had not had a sexual partner in the past 3 months $(64.00 \%)$, were unemployed or housewives $(63.30 \%)$ and living with friends $(60.90 \%)$. In the majority of subjects their religion was Islam (59.80\%), followed by Buddhism (16.10\%), Christianity $(8.00 \%)$, Hinduism (4.50\%), Catholicism (3.60\%) and others $(8.10 \%)$ (see Table 1$)$.

\section{PROCEDURE}

Through the internet and the introduction of some workers at NGOs, we contacted some religious-based NGOs that provide services to PLWH for their permission to conduct this study. We provided a proposal of the study, a sample of the informed consent form for PLWH and a sample of the questionnaire for the consideration of these NGOs. We obtained permission from five NGOs. Then we employed the purposive sampling method to recruit participants. Purposive sampling is a type of non-probability sampling method where the selection of the sample is based on the fit of the sample for the purpose of the study with special inclusion and exclusion criteria (Daniel, 2011). In this report, only those PLWH either staying in shelter homes or visiting the drop-in centres of these five NGOs and have a religion were recruited.

We briefed all PLWH about the aims of this study and their right not to participate. We only recruited those who agreed to participate and signed the informed consent form. Questionnaires were then distributed to the participants to fill in. Researchers or the contact persons of the NGOs stayed to assist with any problems that occurred while the participants were answering the questionnaires.

\section{QUESTIONNAIRE}

Demographic information. In this section, participants were asked to fill in some information that was

Table 1

Demographic characteristics of respondents $(N=117)$

\begin{tabular}{|c|c|c|}
\hline \multirow{2}{*}{ Gender } & Male & $74.80 \%$ \\
\hline & Female & $25.20 \%$ \\
\hline \multirow{2}{*}{ Ages } & 40 or below & $50.40 \%$ \\
\hline & above 40 & $49.60 \%$ \\
\hline \multirow{2}{*}{ Employment } & Employed & $37.70 \%$ \\
\hline & Housewife or unemployed & $62.30 \%$ \\
\hline \multirow{3}{*}{$\begin{array}{l}\text { Living } \\
\text { arrangement }\end{array}$} & Alone & $11.40 \%$ \\
\hline & With family & $27.19 \%$ \\
\hline & With friends & $61.41 \%$ \\
\hline \multirow{3}{*}{$\begin{array}{l}\text { Sexual } \\
\text { orientation }\end{array}$} & Heterosexual & $48.40 \%$ \\
\hline & Homosexual & $40.70 \%$ \\
\hline & Bisexual & $10.90 \%$ \\
\hline \multirow{3}{*}{$\begin{array}{l}\text { Medical } \\
\text { adherence }\end{array}$} & Yes & $78.60 \%$ \\
\hline & No & $21.40 \%$ \\
\hline & Malay & $54.30 \%$ \\
\hline \multirow[t]{2}{*}{ Ethnic } & Chinese & $29.30 \%$ \\
\hline & Others & $16.40 \%$ \\
\hline \multirow{2}{*}{ Religion } & Muslim & $59.80 \%$ \\
\hline & Others & $40.20 \%$ \\
\hline \multirow{2}{*}{$\begin{array}{l}\text { HIV } \\
\text { duration }\end{array}$} & 60 months or below & $47.90 \%$ \\
\hline & Above 60 months & $52.10 \%$ \\
\hline \multirow{2}{*}{ Relationship } & Single, divorced or widowed & $31.00 \%$ \\
\hline & Married or in a relationship & $69.00 \%$ \\
\hline \multirow{2}{*}{ Drug addict } & Yes & $24.10 \%$ \\
\hline & No & $75.90 \%$ \\
\hline \multirow{2}{*}{$\begin{array}{l}\text { Commercial } \\
\text { sex workers }\end{array}$} & Yes & $6.10 \%$ \\
\hline & No & $93.90 \%$ \\
\hline
\end{tabular}

Religious coping and health locus of control 
Poh Chua Siah, Jiunn Han Tan relevant to their background, such as gender, education and employment status.

Quality of life. The HAT-QoL scale includes 34 items and measures nine dimensions (Horizons, n.d.): overall function (six items), life satisfaction (four items), health worries (four items), financial worries (three items), medication worries (five items), HIV mastery (two items), disclosure worries (five items), feelings about doctors or provider trust (three items) and sexual function (two items). Participants needed to circle a number from one to five to indicate how often they had had such feelings in the past four weeks. Scores on each subscale were recorded on a scale from 0 to 100 . A higher score indicated a better QoL. In this report, we only include overall function QoL in the analyses since it is a combination of physical, role and social QoL (Holmes \& Shea, 1999). Cronbach's $\alpha$ reliabilities of the overall function QoL are .77 in this report.

Brief Religious Coping scale. The Brief Religious Coping scale has two subscales: positive religious coping (Items 1 to 7) and negative religious coping (Items 8 to 14) (Pargament et al., 2011). The positive religious coping subscale was used to assess to what extent the individuals established a sense of connectedness, and a secure relationship with a higher power or God, whereas the negative religious coping subscale is about the individuals' religious or spiritual struggle, tension, and conflict with a higher power or religious congregation. Participants were asked to rate the extent of their use of coping strategies when dealing with difficult life situations on a four-point Likert scale ranging from not at all (1) to a great deal (4). A higher score indicates that an individual uses religious coping frequently. The sample items under the positive subscale are "looked for a stronger connection with a higher power" and "asked forgiveness for my sins", whereas sample items under the negative subscale are "wondered whether my congregation had abandoned me" and "felt punished by a higher power for my lack of devotion". Cronbach's $\alpha$ in this report are .87 for positive religious coping subscales and .82 for the negative religious coping subscale.

God HLoC. The God HLoC scale itself has six items and it measures the God externality (Wallston et al.,
1999). All items were attempted by the participants through a six-point Likert scale of: strongly disagree (1), moderately disagree (2), slightly disagree (3), slightly agree (4), moderately agree (5), strongly agree (6). Cronbach's $\alpha$ in this report is .87 .

\section{RESULTS}

\section{CORRELATIONS BETWEEN RELIGIOUS COPING, GOD HEALTH LOCUS OF CONTROL AND OVERALL FUNCTION QUALITY OF LIFE}

As shown in Table 2, the results of Pearson correlations show that both positive religious coping and negative religious coping were found to be associated with God HLoC, $r=.63, p<.001$ and $r=.32, p<.001$ respectively, in order. Nonetheless, positive religious coping was not significantly correlated with overall function QoL, $r=-.11, p=.918$, whereas negative religious coping was significantly correlated with overall function QoL, $r=-.29, p=.002$. No significant correlation was found between God HLoC and overall function QoL, $r=.07, p=.479$.

\section{GOD HEALTH LOCUS OF CONTROL, RELIGIOUS COPING AND OVERALL FUNCTION QUALITY OF LIFE}

According to the results of the correlations, it seems that negative religious coping could be the mediator of the effects of God HLoC on overall function QoL. The results meet the three conditions of mediation proposed by Baron and Kenny (1986), that God HLoC is significantly related to negative religious coping, negative religious coping is significantly related to overall function QoL, and the relationship of God HLoC to overall function QoL diminishes when negative religious coping is in the model.

A nonparametric, resampling approach with 2,000 resamples was therefore used to examine the statistical significance of the indirect effect by deriving the $95 \%$ confidence intervals for the indirect effects of

Table 2

Correlations among religious copings, God health locus of control and overall function quality of life (QoL)

\begin{tabular}{|c|c|c|c|c|}
\hline & $M$ & $S D$ & $\begin{array}{c}\text { God health } \\
\text { locus of control }\end{array}$ & $\begin{array}{l}\text { Overall function } \\
\text { QoL }\end{array}$ \\
\hline Positive religious coping & 21.36 & 5.51 & $.625^{* *}$ & -.010 \\
\hline Negative religious coping & 14.47 & 5.39 & $.320^{* *}$ & $-.286^{* *}$ \\
\hline God health locus of control & 24.57 & 7.96 & - & .066 \\
\hline Overall function & 57.51 & 23.01 & .066 & - \\
\hline
\end{tabular}

Note. ${ }^{* *} p<.01$ 
God HLoC via negative religious coping on change in overall function QoL (Preacher \& Hayes, 2004). SPSS Macro provided by Preacher and Hayes was used in the analysis. The true indirect effect of God HLoC was estimated to lie between -0.56 and -0.13 with $95 \%$ confidence (Table 3 ). Zero is not in the $95 \%$ confidence interval, and thus both the indirect effects are significantly different from zero at $p<.05$. In other words, negative religious coping mediates the relationships between God HLoC and overall function QoL.

\section{DISCUSSION}

This report aims to explore the relationships of God HLoC, religious coping and HQoL among PLWH. To our knowledge, no study has been conducted to examine the relationships between these three variables among PLWH.

For the first research question, the results show that negative religious coping is negatively correlated with overall function QoL. In other words, the less people use negative religious coping, the better their QoL. This result is consistent with other studies that found significant associations between negative religious coping and poorer mental health (Pargament \& Raiya, 2007).

Nonetheless, it is surprising to find the non-significant result between positive religious coping and overall function QoL. These results are different from some studies that have found significant associations between positive religious coping and some desired mental health indicators (Smith, Pargament, Brant, \& Oliver, 2000; Tarakeshwar \& Pargament, 2001). A possible explanation for this difference is relevant to the perception of HIV that HIV is usually regarded as a punishment from the highest power (Hasanah, Zaliha, \& Mahiran, 2011) and thus PLWH do not believe the use of positive religious coping will change their sins. Another possible explanation is that this relationship may be moderated by the religiosity of participants whereby a positive relationship between positive religious coping and HQoL is more likely to be found among those who have high religiosity. Nonetheless, as no measurement of religiosity was included in this study, further study is needed to explore this possibility.

Secondly, the results of the bootstrapping procedure show that negative religious coping is the mediator of the indirect effect of God HLoC on overall function QoL. In other words, those PLWH who have a high God HLoC are more likely to use negative religious coping, and their frequent use of negative religious coping has a negative impact on their overall function QoL.

In conclusion, the results of the report show the significant relationships between God HLoC, negative religious coping and overall function $\mathrm{HQOL}$, which suggest that the frequent use of negative religious coping may influence the overall function QoL of PLWH, especially for those PLWH who have a high God HLoC. Therefore, the programmers at the NGOs should not just strengthen the religious beliefs among PLWH, such as the understanding of religious knowledge and praying, but also reduce their use of negative religious coping, so that the overall function QoL of PLWH can be improved.

Nonetheless, the interpretation of the report needs to be cautious, since the PLWH in this study were from different religious backgrounds. Future studies

Table 3

Regression results for simple mediation on God health locus of control (HLoC)

\begin{tabular}{|c|c|c|c|c|}
\hline & $B$ & $S E$ & $t$ & $p$ \\
\hline \multicolumn{5}{|l|}{ Direct and total effect } \\
\hline Overall function QoL regressed on God HLoC & 0.21 & 0.06 & 0.77 & .441 \\
\hline Negative religious coping regressed on God HLoC & 0.03 & 0.01 & 3.66 & .004 \\
\hline $\begin{array}{l}\text { Overall function QoL regressed on negative religious coping, } \\
\text { controlling for God HLoC }\end{array}$ & -10.21 & 2.82 & -3.63 & $<.001$ \\
\hline $\begin{array}{l}\text { Overall function QoL regressed on God HLoC, controlling for } \\
\text { negative religious coping }\end{array}$ & 0.53 & 0.27 & 1.94 & .054 \\
\hline LL 95\% Cl UL 95\% C & $z$ & & $p$ & \\
\hline
\end{tabular}

Indirect effect and significance using normal distribution

\begin{tabular}{|c|c|c|c|c|c|}
\hline Sobel & -0.32 & 0.13 & -0.57 & -0.07 & .011 \\
\hline & & & $S E$ & LL 95\% Cl & UL $95 \% \mathrm{Cl}$ \\
\hline
\end{tabular}

Bootstrap results for indirect effect

Effect

$-0.32$

0.11

$-0.56$

$-0.13$

Religious coping and health locus of control 
may consider recruiting more PLWH from a religion other than Islam, such as Buddhism and Hinduism, so that more comparisons can be made. In addition, future studies may consider including a measure of religiosity to examine whether the relationships between religious coping strategies and QoL are moderated by the religiosity of respondents.

\section{RefERENCES}

Poh Chua Siah, Jiunn Han Tan

Ano, G. G., \& Vasconcelles, E. B. (2005). Religious coping and psychological adjustment to stress: A meta-analysis. Journal of Clinical Psychology, 61, 461-480. doi: 10.1002/jclp.20049

Bandura, A. (1977). Self-efficacy: toward a unifying theory of behavioral change. Psychological Review, 84, 191-215.

Baron, R. M., \& Kenny, D. A. (1986). The moderator-mediator variable distinction in social psychological research: Conceptual, strategic, and statistical considerations. Journal of Personality and Social Psychology, 51, 1173.

Cella, D. F., \& Bonomi, A. E. (1995). Measuring quality of life: 1995 update. Oncology, 9, 47-60.

Collins, E. J., Hogan, T. P., \& Desai, H. (1991). Measurement of therapeutic response in schizophrenia: a critical survey. Schizophrenia Research, 5, 249-253.

Daniel, J. (2011). Sampling essentials: practical guidelines for making sampling choices. Thousand Oaks, CA: Sage Publications.

Franklin, M. D., Schlundt, D. G., \& Wallston, K. A. (2008). Development and validation of a religious health fatalism measure for the African-American faith community. Journal of Health Psychology, 13, 323-335. doi: 10.1177/1359105307088137

Gore-Felton, C., Koopman, C., Spiegel, D., Vosvick, M., Brondino, M., \& Winningham, A. (2006). Effects of quality of life and coping on depression among adults living with HIV/AIDS. Journal of Health Psychology, 11, 711-729. doi: 10.1177/1359105306066626

Hansen, N. B., Vaughan, E. L., Cavanaugh, C. E., Connell, C. M., \& Sikkema, K. J. (2009). Health-related quality of life in bereaved HIV-positive adults: relationships between HIV symptoms, grief, social support, and Axis II indication. Health Psychology, 28, 249-257. doi: 10.1037/a0013168

Hasanah, C. I., Zaliha, A. R., \& Mahiran, M. (2011). Factors influencing the quality of life in patients with HIV in Malaysia. Quality of Life Research, 20, 91-100. doi: 10.1007/s11136-010-9729-y

Holmes, W. C., \& Shea, J. A. (1997). Performance of a new, HIV/AIDS-Targeted Quality of Life (HATQoL) Instrument in Asymptomatic Seropositive Individuals. Quality of Life Research, 6, 561-571. doi: 10.1023/A:1018464200708
Holmes, W. C., \& Shea, J. A. (1999). Two approaches to measuring quality of life in the HIV/AIDS population: HAT-QoL and MOS-HIV. Quality of Life Research, 8, 515-527. doi: 10.1023/A:1008931006866

Horizons. (n.d.). AIDSQuest: the HIV/AIDS survey library. Retrieved from http://www.popcouncil.org/ Horizons/ORToolkit/AIDSQuest/index.html

Joint United Nations Programme on HIV/AIDS. (2014). 01/2014 UNAIDS 2014 Fact Sheet. Retrieved from http://www.unaids.org/sites/default/ files/en/media/unaids/contentassets/documents/ factsheet/2014/20140716_FactSheet_en.pdf

Kinney, A. Y., Emery, G., Dudley, W. N., \& Croyle, R. T. (2002). Screening behaviors among African American women at high risk for breast cancer: do beliefs about god matter? Oncology Nursing Forum, 29, 835-843. doi: 10.1188/02.ONF.835-843

Kuwahara, A., Nishino, Y., Ohkubo, T., Tsuji, I., Hisamichi, S., \& Hosokawa, T. (2004). Reliability and validity of the multidimensional health locus of control scale in japan: relationship with demographic factors and health-related behavior. The Tohoku Journal of Experimental Medicine, 203, 3745. doi: 10.1620/tjem.203.37

Lee, M., Nezu, A. M., \& Nezu, C. M. (2014). Positive and negative religious coping, depressive symptoms, and quality of life in people with HIV. Journal of Behavioral Medicine, 37, 921-930. doi: 10.1007/s10865-014-9552-y

Levenson, H. (1972). Distinctions within the concept of internal-external control: development of a new scale. Proceedings of the Annual Convention of the American Psychological Association, 7, 261-262.

Lorenz, K. A., Cunningham, W. E., Spritzer, K. L., \& Hays, R. D. (2006). Changes in symptoms and health-related quality of life in a nationally representative sample of adults in treatment for HIV. Quality of Life Research, 15, 951-958. doi: 10.1007/ s11136-005-6010-x

McConnell, K. M., Pargament, K. I., Ellison, C. G., \& Flannelly, K. J. (2006). Examining the links between spiritual struggles and symptoms of psychopathology in a national sample. Journal of Clinical Psychology, 62, 1469-1484. doi: 10.1002/jclp.20325

Pargament, K., Feuille, M., \& Burdzy, D. (2011). The brief RCOPE: current psychometric status of a short measure of religious coping. Religions, 2, 51-76. doi: 10.3390/rel2010051

Pargament, K. I. (1997). The psychology of religion and coping: theory, research, practice. New York: Guilford Press.

Pargament, K. I., Koenig, H. G., Tarakeshwar, N., \& Hahn, J. (2004). Religious coping methods as predictors of psychological, physical and spiritual outcomes among medically ill elderly patients: a two-year longitudinal study. Journal of Health Psychology, 9, 713-730. doi: 10.1177/1359105304045366 
Pargament, K. I., \& Raiya, H. A. (2007). A decade of research on the psychology of religion and coping: things we assumed and lessons we learned. Psyke \& Logos, 28, 742-766.

Preacher, K. J., \& Hayes, A. F. (2004). SPSS and SAS procedures for estimating indirect effects in simple mediation models. Behavior Research Methods, Instruments, \& Computers, 36, 717-731. doi: 10.3758/BF03206553

Préau, M., Vincent, E., Spire, B., Reliquet, V., Fournier, I., Michelet, C., Leport, C., \& Morin, M. (2005). Health-related quality of life and health locus of control beliefs among HIV-infected treated patients. Journal of Psychosomatic Research, 59, 407413. doi: 10.1016/j.jpsychores.2005.06.005

Rotter, J. B. (1954). Social learning and clinical psychology (Vol. 9). Englewood Cliffs, NJ, US: Prentice-Hall, Inc.

Smith, B. W., Pargament, K. I., Brant, C., \& Oliver, J. M. (2000). Noah revisited: religious coping by church members and the impact of the 1993 midwest flood. Journal of Community Psychology, 28, 169-186. doi: 10.1002/(SICI)15206629(200003)28:2<169::AID-JCOP5>3.0.CO;2-I

Tarakeshwar, N., \& Pargament, K. I. (2001). Religious coping in families of children with autism. Focus on Autism and Other Developmental Disabilities, 16, 247-260. doi: 10.1177/108835760101600408

The WHOQOL Group. (1998). The World Health Organization quality of life assessment (WHOQOL): development and general psychometric properties. Social Science \& Medicine, 46, 1569-1585. doi: 10.1016/S0277-9536(98)00009-4

Trevino, K. M., Pargament, K. I., Cotton, S., Leonard, A. C., Hahn, J., Caprini-Faigin, C. A., \& Tsevat, J. (2007). Religious coping and physiological, psychological, social, and spiritual outcomes in patients with HIV/AIDS: cross-sectional and longitudinal findings. AIDS and Behavior, 14, 379-389. doi: 10.1007/s10461-007-9332-6

Wallston, K. A., Malcarne, V. L., Flores, L., Hansdottir, I., Smith, C. A., Stein, M. J., Weisman, M. H., \& Clements, P. J. (1999). Does God determine your health? The God locus of health control scale. Cognitive Therapy and Research 23, 131-142. doi: 10.1023/A:1018723010685

Wallston, K. A., Stein, M. J., \& Smith, C. A. (1994). Form C of the MHLC scales: a condition-specific measure of locus of control. Journal of Personality Assessment, 63, 534-553. doi: 10.1207/s15327752jpa6303_10

Wallston, K. A., Wallston, B. S., \& DeVellis, R. (1978). Development of the multidimensional health locus of control (MHLC) scales. Health Education \& Behavior, 6, 160-170. doi: 10.1177/109019817800600107

World Health Organization. (1997). Measuring quality of life: the world health organization quality of life instruments. Retrieved from http://www.who. int/mental_health/media/68.pdf
Religious coping and health locus of control 